\title{
De la danza y el baile en tiempos de Cervantes
}

\author{
About Dance and Trip in the Times of Cervantes
}

José F. Ortega

Universidad de Murcia

jfortega@um.es

\section{RESUMEN}

Desde un punto de vista semántico, actualmente apenas distinguimos entre la danza y el baile; en cambio, en tiempos de Cervantes ambos términos se utilizaban de modo diferenciado. Por lo general, la danza se asociaba a la música culta, desarrollándose en el entorno social de las clases altas; el baile, por su parte, a la música popular y a las gentes más humildes. A partir de una amplia selección de textos de naturaleza diferente ahondaremos en esta cuestión tratando de aislar los rasgos que hicieron posible distinguir entre ambas voces.

Palabras clave: Baile, danza, sarao, danzas de cuenta, danzas de cascabel.

\begin{abstract}
From a semantic point of view, at the moment we hardly distinguish between the dance and the dance; in the time of Cervantes, both terms were used differently. In general, dance was associated with cultured music, developed in the social environment of the upper classes; the dance, on the other hand, to the popular music and to the humblest people. From a wide selection of texts of different nature, we will delve into this question trying to isolate the features that made it possible to distinguish between both voices.
\end{abstract}

Key words: Dance, Trip, Sarao, Account Dances, Rattlesnake Dances.

Ortega, J. F. (2017). De la danza y el baile en tiempos de Cervantes. Cuadernos de Investigación Musical, 2, 5-17. 


\section{JOSÉ F. ORTEGA}

\section{INTRODUCCIÓN}

El erudito, bibliógrafo y académico de la RAE Don Emilio Cotarelo y Mori (1911: CLXV) defendía que "las voces bailar y danzar eran correlativas, pero no sinónimas", es decir, se acostumbraba a emplearlas en concurrencia, citando simultáneamente una detrás de la otra, pero sin llegar a confundirlas. Su opinión venía respaldada por el testimonio de diversos autores, entre ellos, Cervantes.

Efectivamente, son varios los pasajes cervantinos en los que tal sucede. Recordemos, por ejemplo, el famoso capítulo XX de la segunda parte del Quijote (1615) “donde se cuentan las bodas de Camacho el rico". Describe allí con detalle el escritor una "danza de artificio y de las que llaman habladas", indicando en un momento dado que "todas las demostraciones que -hacían eran al son de los tamborinos, bailando y danzando concertadamente" .

Otro ejemplo puede encontrarse en el capítulo VIII del libro tercero de su última novela, Los trabajos de Persiles y Sigismunda, donde una doncella labradora dice de Mari Cobeña que "está encinta, y no está para danzar ni bailar".

\section{DANZA VERSUS BAILE}

Pero hay otro pasaje del escritor alcalaíno de especial interés para el tema que nos ocupa. Pertenece al capítulo XLVIII de la segunda parte del Quijote, en el que Cervantes pone en escena a doña Rodríguez. La dueña relata al insigne caballero cómo, tras quedar viuda, vino a parar junto con su hija al servicio de la duquesa. De su retoño, ya crecidita, enumera las cualidades: "canta como una calandria, danza como el pensamiento, baila como una perdida". Y, como colofón, añade: "lee y escribe como un maestro de escuela, y cuenta como un avariento". En definitiva, todo un compendio de virtudes. La primera parte de la sentencia, en la que Cervantes opone la sutilidad de la danza frente a la lubricidad del baile, será utilizada en un futuro como argumento por quienes defiendan las diferencias entre ambos términos.

El humanista y filólogo Juan Antonio Pellicer - a quien debemos la primera edición rigurosa del Quijote, publicada en 1797 en varios volúmenes con numerosas y enjundiosas notas- glosa esta célebre frase cervantina con el siguiente comentario:

Distinguíanse con efecto en tiempo de Cervantes las danzas de los bailes, que ahora se confunden. Llamábanse danzas los bailes graves y autorizados, como eran el turdión, la pavana, madama Orliens, el piedelgibao, el rey don Alonso el Bueno, el caballero, etc. Bailes se llamaban los populares y truhanescos, como eran la zarabanda, la chacona, las gambetas, el rastrojo, el pésame dello y más, la gorrona, la pipironda, el villano, el pollo, el hermano Bartolo, el guineo, el colorín colorado, etc. (Cervantes, 1799: 341).

\footnotetext{
${ }^{1}$ En éste, como en todos los textos que se citan, hemos optado por regularizar la ortografía y la puntuación, adaptando ambas al uso actual.
}

Cuadernos de Investigación Musical, 2017, junio, $\mathrm{n}^{\circ}$ 2, págs. 5-17.

ISSN: 2530-6847 


\section{DE LA DANZA Y EL BAILE EN TIEMPOS DE CERVANTES}

El murciano Diego Clemencín, otro renombrado cervantista y autor de una magna edición del Quijote publicada entre 1833 y 1839, comenta también la mencionada frase, trayendo a colación la opinión expresada por Juan Antonio Pellicer. Recuerda, no obstante, que "Covarrubias no hizo esta distinción entre bailes y danzas, y llama bailes al del rey don Alonso, la gallarda, los Gelves, el caballero, el villano y la pavana" (Cervantes, 1836: 466467).

Efectivamente, Sebastián de Covarrubias, aunque coetáneo de Cervantes, no parece hacer especial distinción entre ambos en su Tesoro de la lengua castellana o española (1611). No obstante, cuestionándose el origen de la palabra, hipotetiza que "danza" (casi ducanza, matiza) provenga de ducendo porque -explica Covarrubias- "va uno delante que es el que la guía y los demás le siguen” (Covarrubias, 1611: 595). Para el lexicógrafo, por tanto y a diferencia del baile, la danza implicaría una actividad grupal con alguien al frente conduciéndola.

Pero lo cierto es que Covarrubias emplea indistintamente los términos "baile" y "danza". De este modo, dice de la zarabanda que era un "baile bien conocido [...] alegre y lascivo" (Covarrubias, 1611: 528, 2); y a la vez define la gallarda -tenida por la danza preferida de los reyes y nobles- como un "baile castellano dicho así por su cantarcico: Dama gallarda, mata colón, mucho te quiere el Emperador" (Covarrubias, 1611: 851, 1).

Como equivalentes a la danza, habla Cervantes de los "bailes honestos". Lo hace en el capítulo 8 del libro I de Persiles y Sigismunda, en el que el personaje de Rutilio, maestro de danza, narra que un caballero de su ciudad lo contrató para que enseñase a danzar a la hija de éste pues pretendía casarla con caballero florentino: aunque no era muy espabilada, quería entregársela "adornada de gracias adquiridas", ya que "la gentileza, gallardía y disposición del cuerpo en los bailes honestos, más que en otros pasos se señalan".

El sevillano Rodrigo Caro, en sus Días geniales o lúdricos (1626), afirmaba "que en la danza las gesticulaciones y meneos son honestos y varoniles"; en el baile, en cambio, "lascivos y descompuestos" (Caro, 1884: 60).

Casi un decenio antes, el murciano Alonso Cano y Urreta, Comendador de Montachuelos, Señor de las villas de Monteagudo y Ceutí y Capitán General de la Armada Real del Estrecho, ya lamentaba en sus Días de jardín (1619) que la virilidad inherente a la danza, considerada como un buen ejercicio preparatorio para la guerra, trocó con el tiempo en lascivia:

El saltar o danzar, que es una misma cosa, mientras no desdijo de su principio, fue el ejercicio más glorioso pues, imagen y retrato de la guerra, juntó al deleite el provecho sin peligro [...] Quiso la danza fortalecer los miembros y sacar diestros y ligeros soldados: y así ensayó guerras. Veneró luego con su hermosura los dioses, pasó a deleitar con su gracia los convites, y olvidado su virtuoso nacimiento, salió el mayor enemigo de la castidad y el ejercicio más vituperado de santos y prudentes varones. Achacó Roma este mal a Cádiz y a Andalucía: de quien en vez del saltar varonil y fuerte, mudó el baile su perfección en vueltas de brazos y meneos lascivos (Cano y Urreta, 1619: 39). 


\section{JOSÉ F. ORTEGA}

González de Salas, en su Nueva idea de la tragedia antigua (1633), ofrece una descripción más precisa de la diferencia entre el baile y la danza. Dice de esta última que es "el movimiento de los pies, medido y concertado, que regularmente sigue el compás de algún género de música". A diferencia del baile, "las danzas son de movimientos más mesurados y graves, y en donde no se usa de los brazos, sino de los pies solos". Los bailes, en cambio, concluye el humanista madrileño, "admiten gestos más libres, de los brazos y de los pies juntamente" (González de Salas, 1778: 171).

Miguel Querol recoge una lista de danzas y bailes citados por Cervantes en sus obras. Entre las primeras están: el Rey don Alonso, la gallarda, la danza morisca y el turdión. Entre los segundos: el canario, el contrapás, la chacona, el escarramán, la folía, las gambetas, la jácara o jacarandina, la perra mora, el pésame dello, el polvillo, la seguidilla, el villano, el zambapalo y la zarabanda (Querol, 2005: 114 y ss.). A estos últimos añade Cotarelo y Mori el rastreado y el zapateado (Cotarelo y Mori, 1911: CCLVIII y CCLXV).

El mencionado Rodrigo Caro, que nombra además bailes como la carretería, la topona, el Juan Redondo o el guiriguirigay, los tacha todos de lascivos, afirmando que "parece que el Demonio los ha sacado del Infierno" (Caro, 1884: 64):

Una idea, la del origen demoniaco de los bailes, que ya había dejado caer el propio Cervantes en el entremés titulado La Cueva de Salamanca:

Cristina. Basta, que también los diablos son poetas.

Barbero. Y aun todos los poetas son diablos.

Pancracio. Dígame, señor mío, pues los diablos lo saben todo, ¿dónde se inventaron todos estos bailes de las zarabandas, zambapalo y de ello me pesa, con el famoso del nuevo escarramán?

Barbero. ¿A dónde? En el infierno: allí tuvieron su origen y principio.

También en la novela de Luis Vélez de Guevara El diablo cojuelo (1641), el infernal protagonista se atribuye como mérito en su tarjeta de presentación haberlos traído al mundo, añadiendo algunos nombres más a la lista:

Yo traje al mundo la zarabanda, el deligo, la chacona, el bullicuzcuz, las cosquillas de la capona, el guiriguirigay, el zampapalo, la mariona, el avilipinta, el pollo, la carretería, el hermano Bartolo, el carcañal, el guineo, el colorín colorado; yo inventé las pandorgas, las jácaras, las palapatas, los comos, las mortecinas, los títeres, los volatines, los saltambancos, los maesecorrales; y, al fin, yo me llamo el Diablo Cojuelo.

Volviendo a las diferencias entre el baile y la danza, ya en el siglo XVIII, el Diccionario de Autoridades presenta ambas voces estrechamente emparentadas, aunque aprecia una sutil diferencia entre ellas pues, si bien define la danza como un baile, de inmediato matiza, "baile serio". Y en la entrada de la correspondiente forma verbal, habla también de "bailar con gravedad". 


\section{DE LA DANZA Y EL BAILE EN TIEMPOS DE CERVANTES}

Para Pedro María de Olive, el polifacético murciano autor de un Diccionario de sinónimos de la lengua castellana publicado en Madrid en 1843, "la danza expresa más que el baile, e indica más artificio, complicación, cultura, delicadeza, riqueza y lujo" (Olive, 1852: 184). Además, asegura, "siempre se verifica entre mayor número de personas, y se hace acompañada y animada con la música, lo cual no es absolutamente preciso en el baile" (Olive, 1852: 184). Olive define la danza como "una composición estudiada, preparada, dispuesta, donde hay un objeto, un plan, una acción expresada y representada mudamente sólo con los gestos, los movimientos y las posturas" (Olive, 1852: 185). No obstante, advierte que "en el uso común suelen confundirse muchas veces ambas palabras, y llamarse baile a las que son propiamente danzas" (Olive, 1852: 185).

El sevillano Roque Barcia, destacado miembro del movimiento cantonalista, no comparte la opinión de Olive, que rechaza sin nombrar explícitamente a su autor:

Se ha dicho por persona muy autorizada que "la danza expresa más que el baile, e indica más artificio, complicación, cultura, delicadeza, riqueza y lujo". Mucho nos duele tener que objetar a escritores muy respetables, pero la verdad y la lengua ante todo. Aquella opinión es contraria, evidentemente contraria a la filosofía, a la historia y al lenguaje (Barcia, 1870: 93).

Para Barcia, "el baile es el todo, el género. La danza es la parte, la especie. Todas las danzas constituyen el baile. El baile es reunión de todas las danzas" (Barcia, 1870: 96).

El escritor, periodista y magistrado aragonés Julio Monreal, publicó en dos entregas, correspondientes a los números XXXI y XXXII de la revista La Ilustración Española y Americana (22 y 30 de agosto de 1874) un artículo titulado "Costumbres del siglo XVII: los bailes de antaño". Monreal defiende que nuestros antepasados diferenciaban claramente las danzas de los bailes:

[...] pues las primeras eran por todos admitidas y de ninguno motejadas, como que nada más argüían honesto donaire y gallardía en quien las cursaba, mientras los bailes merecían el anatema de los timoratos y temerosos de Dios, como cosa que sólo provocaba lascivia (Monreal, 1874: 506).

En qué se distinguían unas de otros, afirma Monreal:

La diferencia entre las danzas y los bailes estaba en que las primeras, generalmente más antiguas en su origen, eran graves y mesuradas, luciéndose en ellas más que nada la destreza de los pies, y los segundos retozones, triscadores y revoltosos, ponían en continua agitación y picaresco traqueteo, no los pies sólo, sino los brazos y el cuerpo todo, de manera tan gárrula, descomedida y desgarrada, que no había más que pedir (Monreal, 1874: 506). 


\section{JOSÉ F. ORTEGA}

En respuesta a los artículos de Monreal, Francisco Asenjo Barbieri publicó, también en La Ilustración Española y Americana ( $\mathrm{n}^{\circ}$ XLIII, 1877), un escrito titulado "Danzas y bailes en España en los siglos XVI y XVII" en el que matiza algunas de las afirmaciones vertidas por el aragonés. Esto dio origen a una controversia de réplica y contrarréplica que, con la misma revista como marco, se prolongó durante un tiempo y a la que María del Carmen García Matos dedicó su atención en uno de sus trabajos (García-Matos, 1996: 121-134).

En puridad, Barbieri no alude a la diferencia entre danza y baile, aunque sí distingue entre las "danzas de cuenta", es decir, la danza culta, de figuras, explicada con detalle en los tratados al uso; y las "danzas de cascabel", de movimientos no reglados y, en la práctica, equiparable a los bailes. Y señala, además, cómo se hacían acompañar unas y otros:

Las danzas de cuenta se bailaban por lo general al son de las vihuelas de mano o de arco, al del arpa o de otros instrumentos aristocráticos, sin canto de voz humana; pero en las danzas de cascabel y en los llamados bailes hacían generalmente el papel principal los romances, jácaras, coplas y seguidillas, cantadas con acompañamiento de guitarras, bandurrias, panderos, sonajas u otros instrumentos populares, a cuyo son zapateaban y se hacían pedazos los comediantes entremesistas y el vulgo maleante, con gran contentamiento de las personas de juicio, a quienes, si bien su decoro les impedía poner en práctica los lascivos movimientos de una zarabanda, no por esto dejaban de aplaudirlos con entusiasmo en el teatro o en otro cualquier sitio en que la vieran bailar; y aunque los graves maestros del arte del danzado declamaban sin cesar contra las acciones deshonestas de los bailes populares, estos iban poco a poco infiltrándose en los cortesanos, que, aunque no llegaron a corromperse, recibieron, sin embargo, de aquellos muchos pasos y mudanzas, que los enriquecieron sin quitarles su primitivo decoro (Barbieri, 1994: 357).

En su ensayo La música en tiempos de Cervantes, Miguel Querol sostiene que, por aquel entonces, existían claras diferencias entre ambos vocablos. Sorprende, sin embargo, las acepciones que da de uno y otro. Define la danza como un verdadero arte, en el que "el ritmo es traducido por todo el cuerpo humano, y encarnado, por decirlo así, en todas sus partes: manos, pies, cabeza, cadera, etc.". En los bailes, en cambio, "el movimiento rítmico afecta exclusivamente o casi exclusivamente a los pies" (Querol, 2005: 111). Recordemos que González de Salas lo expresó justo a la inversa, como también hizo Estébanez Calderón.

Conocido popularmente bajo el seudónimo de El Solitario, el conocido autor de las Escenas andaluzas detalla en el artículo intitulado "Un baile en Triana" la esencia del "baile andaluz":

En Andalucía no hay baile sin el movimiento de los brazos, sin el donaire y provocaciones picantes de todo el cuerpo, sin la ágil soltura del talle, sin los quiebros de cintura, y sin lo vivo y ardiente del compás, haciendo contraste con los dormidos y remansos de los cernidos, desmayos y suspensiones (Estébanez, 1847: 203). 


\section{DE LA DANZA Y EL BAILE EN TIEMPOS DE CERVANTES}

En cambio, "el batir de los pies, sus primores, sus campanelas, sus juegos, giros y demás menudencias, es como accesorio al baile andaluz, y no forman, como en la danza, la parte principal" (Estébanez, 1847: 203). Y añade:

La gallarda, el bran de Inglaterra, la pavana, la haya y otras danzas antiguas españolas fundaban sólo su vistosidad y realce en la primera soltura y batir de los pies, y en el aire y galanía del pasear la persona. Allí no había pasión, delirio, frenesí, como se pretenden pintar en todos los bailes que desde muy antiguo han sido peculiares a España, singularmente en las provincias meridionales. Aquellas danzas tenían su lugar en la gala ceremoniosa del sarao; los bailes para el desenfado del festín, para la libertad del teatro (Estébanez, 1847: 203).

Volviendo a Querol, el compositor y musicólogo catalán señala que la danza "cuando pierde ritmo vital [...] se convierte automáticamente en baile". Por su parte, el baile, cuando "aumenta su ritmo vital, se convierte en danza o en orgía, según los casos" (Querol, 2005: 111). Se entiende así que, en época de Cervantes, un mismo ritmo se etiquete unas veces como danza y otras, como baile: será danza cuando la ejecuten "bailarines profesionales u otros que las han aprendido conforme a las reglas del danzado"; baile, cuando lo haga el pueblo, "a su manera, prescindiendo del ceremonial y de los detalles que hacen de la danza un arte"; o tocata religiosa, "cuando se ejecute en la iglesia" (Querol, 2005: 111). Más adelante, incide de nuevo en esta cuestión:

Sobre los bailes y danzas citados por Cervantes en sus obras llegamos a la plena convicción de que en la época del autor de Don Quijote todos los bailes y danzas presentaban dos vertientes: una popular, alegre y callejera, y otras más formal, seria y cortesana (Querol, 2005: 127).

Esta idea ya había sido expuesta por Cotarelo y Mori cuando, tras recoger la definición que del villano da el Diccionario de Autoridades ("tañido de danza española"), comenta: "En nuestros escritores hay bastantes referencias que aclaran el concepto de este baile o danza según la manera burda o cortesana de llevarlo" (Cotarelo y Mori, 1911: CCLXIII).

Algo similar ya se operaba en el campo literario donde, partiendo de un texto previamente conocido, se lo sometía a transformaciones a fin de dotarlo de un sentido moralizante o religioso: se creaban así versiones a lo divino (contrafacta) de poesía de tipo tradicional (Medina-Bocos, 2001: 54) [Cf].

De este modo, por poner algún ejemplo, el villano se canta a lo divino en el auto sacramental El Peregrino, de Joseph de Valdivieso, ya casi a la conclusión de la obra: 


\section{JOSÉ F. ORTEGA}

Si de noche a Dios perdiste,

el mi romero,

que de día le buscar

hecho cordero,

pues hoy al villano dan

carne, vino, sangre y pan (Citado por Cotarelo y Mori, 1911: CCL).

En la mojiganga anónima La Gitanada, de la que hay una edición reciente a cargo de Catalina Buezo (2008: 39-51), también se canta y se baila un villano a lo divino:

Hoy al hombre se lo dan

carne y sangre, vino y pan.

Las gitanas y gitanos

zapatean con las manos [...] (Citado por Cotarelo y Mori, 1911: CCL)

En cambio, Cervantes, en el entremés El Rufián Viudo, ya casi al final, hace pedir a Escarramán que canten (y bailen) el villano a lo burdo:

Escarramán. Vaya el villano a lo burdo, con la cebolla y el pan, y acompáñenme los tres.

Músico. Que te bendiga San Juan.

[Bailan el villano, como bien saben...]

\section{DANZa O BAILE: UNA CUESTIÓN DE CLASE}

En la relación entre la danza y el baile subyace de fondo la cuestión social, la separación entre clases. La danza es cosa de nobles y aristócratas, de las gentes que ejercen u ostentan el poder; el baile, en cambio, de las clases populares.

Maria Grazia Profeti (1995: 205-213) ha analizado la importancia de la danza en la formación de los nobles y caballeros, aunque ya antes lo había hecho Barbieri:

En aquellos siglos no se consideraba completa la educación de un caballero o de un hidalgo si éste, además de cursar las letras, no era muy diestro en esgrimir, cabalgar, danzar y aun cantar acompañándose con la vihuela o la guitarra, que eran instrumentos diferentes, aunque análogos. El arte del danzado, en particular, se miraba con tal predilección, que hasta las personas más graves y encopetadas lo cultivaban con exquisito esmero en escuelas especiales o privadamente, bajo la dirección de muy hábiles maestros (Barbieri, 1994: 357). 


\section{DE LA DANZA Y EL BAILE EN TIEMPOS DE CERVANTES}

En un divertido pasaje del Quijote (II 62), en el que el caballero andante se ve impelido a danzar hasta el agotamiento, el bueno de Sancho plantea a su señor la siguiente pregunta retórica: "¿Pensáis que todos los valientes son danzadores y todos los andantes caballeros bailarines?”.

Esos “'hábiles maestros” de los que hablaba Barbieri eran los maestros de danzar. Recordemos que Rutilio, en la novela Los Trabajos de Persiles y Sigismunda, en el capítulo 8 del libro I, "donde da cuenta de su vida", se presenta como "maestro de danzar", y no malo pues alardea de que sería "único en él y venturoso, si yo quisiera". Señala, además, la importancia de saber danzar los bailes honestos, pues "a las damas principales les está muy bien saberlos para las ocasiones forzosas que les pueden suceder". Como apunta Covarrubias, existían también las escuelas de danzar "donde los mancebos van a deprender las danzas y los bailes, como la alta y la baja, el canario, la gallarda y el Rey don Alonso" (Covarrubias, 1611: 369).

Se escribieron, además, tratados de danza, como los de Cesare Negri (1604) o Esquivel Navarro (1642) que, como advierte Menéndez Pelayo en su monumental obra Historia de las ideas estéticas en España, publicada entre 1883 y 1891, "se refieren exclusivamente a la danza grave, ceremoniosa y aristocrática, que formaba parte de la educación de los príncipes y grandes señores, y de ningún modo a los bailes populares y picarescos" (Menéndez Pelayo, 2012: 711)2.

Las danzas eran, pues, cosa de la aristocracia, de la gente de calidad, y tenían lugar en las fiestas y en los saraos. Covarrubias define el "sarao" como una "junta de damas y galanes en fiesta principal y acordada, particularmente en los palacios de los reyes y grandes señores"; en ella -añade- "se danza al son de muchos instrumentos músicos y también suele haber música de cantores" (Covarrubias, 1611: 1256, 2).

De los bailes dice, en cambio, Julio Monreal:

[...] la afición y el desvivirse por los bulliciosos bailes pertenecía a la caterva de pícaros, rufos $^{3}$, fregonas ${ }^{4}$ y demás turba del hampa, que se comían las manos tras ellos, inventándolos nuevos cada día, con su música retozona y bullanguera, y su letra condimentada con toda la sal y mostaza que el redomado ingenio de los poetas pícaros sabía dar a los chistes, chufletas y civilidades ${ }^{5}$ de las gentes a quienes quería agradar (Monreal, 1874: 506).

Las danzas, para bailarlas, requieren preparación previa; el baile, por el contrario, surge de manera espontánea. Así se desprende de este pasaje de la comedia cervantina La Gran Sultana Doña Catalina de Oviedo (Jornada III), donde tiene lugar el siguiente diálogo:

\footnotetext{
2 La obra es accesible en la página de la Fundación Ignacio Larramendi (Biblioteca Virtual Menéndez Pelayo) http://www.larramendi.es/menendezpelayo/en/consulta/registro.cmd?id=959 [consultado el 20 de diciembre de 2016].

3 "Hombre que hace tráfico de prostitutas" (RAE).

4 "Mujer tosca e inculta" (RAE).

5 "Miseria, mezquindad, grosería" (RAE).
} 


\section{JOSÉ F. ORTEGA}

$\begin{array}{ll}\text { Músico 2 } & \text { ¿Y sabéis vos danzar? } \\ \text { Madrigal } & \begin{array}{l}\text { Como una mula. } \\ \text { Pero tengo un romance correntío, } \\ \text { que le pienso cantar a la loquesca, } \\ \text { que trata ad longum todo el gran suceso } \\ \text { de la Grande Sultana Catalina. }\end{array} \\ \text { Músico 1 } & \begin{array}{l}\text { ¿Cómo lo sabéis vos? } \\ \text { Su mismo padre } \\ \text { Madrigal }\end{array} \\ \text { Músico 2 } & \begin{array}{l}\text { ¿Qué cantaremos más? } \\ \text { Madrigal }\end{array} \\ & \begin{array}{l}\text { Mil zarabandas, } \\ \text { mil zambapalos lindos, mil chaconas, } \\ \text { y mil pésame de ello, y mil folías. } \\ \text { ¿Quién las ha de bailar? }\end{array} \\ \text { Músico 1 } & \begin{array}{l}\text { La Gran Sultana. } \\ \text { Imposible es que sepa baile alguno, } \\ \text { Madrigal } \\ \text { Músico 2 }\end{array} \\ & \begin{array}{l}\text { porque de edad pequeña, según dicen, } \\ \text { perdió libertad. }\end{array}\end{array}$

A lo que Madrigal responde de manera sentenciosa:

$\begin{array}{ll}\text { Madrigal } & \text { Mirad, Capacho, } \\ & \text { no hay mujer española que no salga } \\ & \text { del vientre de su madre bailadora. }\end{array}$

\section{CONCLUSIÓN}

En la actualidad, las diferencias semánticas entre la danza y el baile son poco nítidas. Nuestros diccionarios hacen prácticamente sinónimas ambas voces, pues comparten un mismo campo semántico, aunque sus etimologías y campos léxicos son diferentes.

Sin embargo, casi de forma unánime los escritores del Siglo de Oro español, entre ellos Cervantes, emplearon los términos danza y baile de modo diferenciado. El arte, las técnicas y recursos puestos en juego, el sometimiento o no a un orden o a ciertas reglas, y también el nivel y el contexto social donde una y otro se desarrollaban distinguían una voz de otra.

Tales diferencias no tardaron, sin embargo, en difuminarse. Se explica así que Esquivel Navarro incluya en su tratado sobre la danza bailes como la zarabanda, la chacona o el rastro (Esquivel, 1642). Convenientemente estilizados, estos bailes fueron muy bien acogidos por la aristocracia y las clases altas. De ahí que, ya en el siglo XIX, Estébanez Calderón, en la escena que lleva por título "El bolero", afirme en relación a la chacona y la zarabanda que, a pesar de su carácter picante y desenvuelto, eran tenidos ambos "por bailes de escuela y cuenta, y no por de botarga y cascabel” (Estébanez, 1847: 27). 


\section{DE LA DANZA Y EL BAILE EN TIEMPOS DE CERVANTES}

En nuestros días, los cruces entre ambas voces son frecuentes, y así hablamos hoy con preferencia de bailarín o bailarina $-\mathrm{y}$ no de danzarín, danzarina o danzante- para referirnos a quien practica el ballet o la danza.

Pero la diferenciación entre una y otra, tal vez de un modo artificioso y harto sutil, también hay quien pretende mantenerla. Por ejemplo, comprobamos que en el diccionario de María Moliner, aunque la primera acepción que se da para la voz "danzar" es "bailar", de inmediato se matiza: "se usa este verbo particularmente cuando se trata de bailes artísticos".

Y podemos ofrecer un ejemplo más. La primera definición que la RAE trae para la vOz "bailador" es la de "bailarín profesional que ejecuta bailes populares de España, especialmente andaluces". En una entrada diferente, recoge también la pronunciación coloquial de este término, "bailaor", cuya acepción es "bailador de música flamenca".

A propósito de este último término, Gamboa y Núñez señalan que "entre los flamencos suele ser muy usual diferenciar bien entre bailaor y bailarín, en relación con la mayor o menor pureza de su arte" si bien, como ellos mismos reconocen, no deja de ser llamativo que el que se otorgue o no el calificativo de bailaor a un artista venga motivado "por razones de origen, raza y formación [...] y no por sus cualidades como intérprete" (Gamboa y Núñez, 2007: 52).

\section{BIBLIOGRAFÍA}

\section{LIBROS}

Barbieri, F. A. (1994) [1877]. "Danzas y bailes en los siglos XVI y XVII", en Emilio Casares Rodicio (ed.). Francisco Asenjo Barbieri, vol. 2 (Escritos). Madrid: ICCMU.

Barcia, R. (1870). Filosofía de la lengua española: sinónimos castellanos. Madrid: Librería de Victoriano Suárez.

Cano y Urreta, A. (1619). Días de jardín. Madrid: Bernardino de Guzmán.

Caro, R. (1884) [1626]. Días geniales o lúdricos. Sevilla: El Mercantil Sevillano.

Cervantes, M. de (1911). El ingenioso bidalgo don Quijote de la Mancha, compuesto por Miguel de Cervantes Saavedra, corregido de nuevo, con nuevas notas, con nuevas viñetas, con nuevo análisis y con la vida del autor nuevamente aumentada, por don Juan Antonio Pellicer, bibliotecario de S.M. y académico de número de la Real Academia de la Historia, parte segunda, tomo VII. Madrid: Gabriel de Sancha. 


\section{JOSÉ F. ORTEGA}

Cervantes, M. de (1836). El ingenioso hidalgo Don Quijote de la Mancha, compuesto por Miguel de Cervantes Saavedra y comentado por don Diego Clemencín, parte II, tomo V. Madrid: D. R. Aguado.

Cotarelo y Mori, E. (1911). Colección de Entremeses, loas, bailes, jácaras y mojigangas desde fines del siglo XVI a mediados del XVIII, vol. I. Madrid: Bailly-Bailliére.

Esquivel, J. (1642). Discursos sobre el arte del danz̧ado. Sevilla: Juan Gómez de Blas.

Estébanez, S. (1847). Escenas andaluzas. Madrid: Imprenta de Don Baltasar González.

González de Salas, J. A. (1778). Nueva idea de la tragedia antigua o ilustración última al libro singular De Poética de Aristóteles Estagirita. Madrid: Antonio de Sancha.

Medina-Bocos, A. (2001). Hacer literatura con la literatura. Madrid: Akal.

Menéndez Pelayo, M. (2012). Historia de las ideas estéticas en España (siglos XVI y XVII), vol. II. Santander: Ed. Universidad de Cantabria.

Negri, C. (1604). Nuove inventioni di balli, Milán: Girolamo Bordone.

Querol, M. (2005) [1948]. La música en la obra de Cervantes. Alcalá de Henares: Centro de Estudios Cervantinos.

\section{ACTAS DE CONGRESOS Y ARTÍCULOS DE ENCICLOPEDIAS O DICCIONARIOS}

Buezo, C. (2008). "Los gitanos en la mojiganga dramática del siglo XVII”. Compostella aurea [recurso electrónico]: Actas del VIII Congreso de la Asociación Internacional del Siglo de Oro, pp. 39-51.

Covarrubias, S. de (1611). Tesoro de la lengua castellana o española. Madrid: Luis Sánchez.

Gamboa, J. M. y Núñez, F. (2007). Flamenco de la A a la Z. Diccionario de términos del flamenco. Madrid: Espasa.

Olive, P. M. de (1852). Diccionario de sinónimos de la lengua castellana. París: Librería de Rosa, Bouret y Cía.

\section{ARTí́CULOS}

García-Matos, M. C. (1996). "Una polémica en torno a las danzas de cuenta y los bailes de cascabel de los siglos XVI y XVII”. Nassarre: Revista Aragonesa de Musicología, vol. 12, no 2, pp. 121-134. 


\section{DE LA DANZA Y EL BAILE EN TIEMPOS DE CERVANTES}

Monreal, J. (1874). "Costumbres del siglo XVII: los bailes de antaño (conclusión)". En La Ilustración Española y Americana, n ${ }^{\circ}$ XXXII (30 de agosto).

Profeti, M. G. (1995). “La danza como «savoir-vivre» en la España del Siglo XVII”, en Rose Duroux (ed.). Les Traites de savoir-vivre en Espagne et au Portugal du Moyen Age à nos jours. Clermont-Ferrand (Francia): Association des publications de la Faculté des lettres et Sciences Humaines de Clermont-Ferrand, pp. 205-213.

Fecha de recepción: 20/12/2016

Fecha de aceptación: 28/02/2017 